\title{
LOS ANTECEDENTES FRANQUISTAS DE LA POLÍTICA DE LA VIVIENDA SOCIAL
}

\author{
Luis Moya González (Dr. Arquitecto - Catedrático DUyOT)
}

Además de otras razones conocidas y publicadas para explicar la "burbuja inmobiliaria" y su consecuente crisis posterior que se produce en España con el cambio de siglo, no se ha reparado suficientemente que el problema de la vivienda no es coyuntural sino que es el resultado de una estructura inmobiliaria, que si no tiene su origen estrictamente después de la Guerra Civil, sí es el momento de su sistematización y puesta en práctica, sin interrupción hasta nuestros días. En efecto el proceso no sufre cambios sustanciales con la nueva democracia, y solo cabría destacar algún intento de nueva legislación sobre el alquiler, la fiscalidad y el control de las viviendas vacías, en el Gobierno de Rodriguez Zapatero de alrededor de 2005; lo cual, sin embargo, ha quedado en suspenso con el advenimiento de la crisis económica.

En una sociedad como la nuestra con insuficientes años de democracia, seguimos confiando, en gran parte, en el providencialismo que provoca la falta de transparencia y la auténtica representatividad, o falta de participación, con la que actúa la Administración Pública. En el problema de la vivienda se traduce en la fe del efecto benéfico de nuevas leyes y retoques en la organización administrativa. En varios países europeos, que nos llevan bastante delantera, han desarrollado desde hace un siglo medidas para que la vivienda social no sea un objeto de especulación, que revisan cada año para ajustarlas a los cambios de la economía. En España no se ha incluido la vivienda social entre las medidas básicas del estado del bienestar, junto a la sanidad, la educación y las pensiones, y ni se ha dado el paso trascendente de excluirla de las actividades lucrativas; por el contrario desde 1940 se ha potenciado el negocio inmobiliario, perdiendo profesionalidad técnica y ganando en arribistas y aficionados, constituyendo el sector básico del "pelotazo". Así ocurre que empresas como los Bancos, compañías de seguros y otras, ajenas al objeto de producción, forman parte espuriamente del tejido productivo de la vivienda social. Un índice del cambio estructural que se ha producido en los últimos 45 años, es que el $89 \%$ de las viviendas están bajo el régimen de propiedad, invirtiendo casi exactamente lo que ocurría en 1940 (en 1950 88\% en alquiler, 6\% en propiedad, y 6\% otros, según Foessa) $)^{47}$, y que de ellas solo un $1 \%$ son propiedad de la Administración, mientras que en Francia es el $44 \%$, Países Bajos 47\% y en Alemania el 57\% (23\%, 35\% y 6\% propiedad de la Administración respectivamente), sobre viviendas principales ${ }^{48}$. Otro dato significativo son las 3,5 MM de viviendas vacías que existen en España ${ }^{49}$, sin contar las de $2^{a}$ residencia, sobre un total de 25 MM, y simultáneamente una fuerte demanda (no calculada estratégicamente por los organismos correspondientes,

\footnotetext{
47 Véase L. Moya Barrios de promoción oficial: Madrid 1939-1975, Ed. COAM, 1983

48 Véase La Vivienda Social en Europa: Alemania, Francia y Países Bajos, Coord. L. Moya, Ed. Mairea 2008

${ }^{49}$ Véase Julio Vinuesa La vivienda vacía en España: un despilfarro social y territorial insostenible, Ed. Scripta Nova, 2008
} 
únicos con suficientes fuentes de información) que provoca una de las tasas de emancipación más tardía de Europa, y conflictos graves en separaciones y divorcios.

Analizando las leyes franquistas se llega a la conclusión que el Estado no construye viviendas sociales realmente hasta la Ley de Viviendas de Renta Reducida y Limitada de 1954. Por tanto en la inmediata posguerra sus dos finalidades principales son ya fomentar la construcción para incentivar la economía y subsidiariamente dotar de vivienda a familias del Régimen, empleados, profesiones liberales y pensionistas. Para apoyar la política de la vivienda se crea el INV (Instituto Nacional de la Vivienda) en 1939, y se aprueba la Ley de Viviendas Protegidas y en 1944 la de Viviendas Bonificables. Debemos entender que la protección y la bonificación tienen como principales destinatarios los organismos oficiales con los objetivos mencionados, apoyando la iniciativa privada para desarrollar la economía. Pero los entes privados no tenían entonces capacidad económica para promover, ni estaban integrados en la nueva estructura económica. Por tanto, excepto algunas excepciones (URBIS y Banús) no se ponen en funcionamiento hasta los años 60, y mientras tanto las actuaciones en vivienda social se concentran en la propia Administración. El paso definitivo se producirá a partir de 1957 con la Ley de Viviendas Subvencionadas, debido a las mayores facilidades que se dan a promotores, y sobre todo a la salida de la autarquía, en relación con los acuerdos militares con EEUU y sus consecuencias de apertura económica al exterior. En este momento cambian sustancialmente los gobiernos de la Falange (era la fracción del Régimen encargada de esta política como parte de su ideología de contenido social, con el refuerzo de la Iglesia por su labor en las parroquias de los barrios de infravivienda) y fuerzas tradicionales de Régimen, para ser sustituidos por la corriente del Opus Dei, la cual, entre otras cosas, pone en marcha los sucesivos Planes de Desarrollo. En este contexto el impulso legislativo y las mayores facilidades que proporciona la Ley de Viviendas Subvencionadas de 1957, con superficies comprendidas entre 35 y $150 \mathrm{~m}^{2}$, cubren un arco grande de demanda que serán absorbidas principalmente por la promoción privada protegida de viviendas para las clases medias, cuya inversión supera el $207 \%$ de la Programada y sin embargo el sector público desciende al $45 \%$ (en el Plan Nacional de Viviendas Protegidas 1944-54 se programan 315.000, en total se construyen 150.000 protegidas y bonificadas; en el Plan 1955-60 se programan 550.000 de tipo social y se construyen la mitad pues la otra mitad están protegidas pero de categoría superior; entre 1961-1971 se programan 2,1 MM y se construyen 1,4 MM, de las cuales son de carácter social un 10\%).

Por otra parte, si observamos detenidamente la estructura organizativa de la promoción oficial de viviendas hasta los años 1960, podemos reconocer que bajo los organismos públicos como la Obra Sindical del Hogar, el INV, los patronatos militares, el Patronato Municipal de la Vivienda, etc. existe una incipiente organización de empresa privada, aunque sus fines no sean económicos sino políticos, con ciertos rasgos en cuanto que sus competencias y campos de aplicación son muy parecidos, compiten entre ellas y tienen un cierto grado de autonomía.

Abundando en la idea de la política de privatización de la vivienda social, observamos que las diferentes denominaciones que han recibido las viviendas protegidas por la Administración en las sucesivas legislaciones, corresponden al tamaño de las mismas, directamente relacionado con su precio, y no con su programa. El tamaño marca el estrato de población al que van dirigidas, es decir 
pocas tienen una finalidad social, excepto las construidas en la década de $1950^{50}$. En 1954 se crea la llamada Vivienda Social a la que se fija el tamaño de $42 \mathrm{~m}^{2}$ útiles, bastante menor a la de leyes anteriores (que aunque no se fija la superficie se construyen mayores de la indicada). También en este año se crea la Vivienda Mínima de 35-58 m², la de Renta Reducida de 74-100 m², la de Renta Limitada de 56-68 m² en su $3^{a}$ categoría y de $65-150 \mathrm{~m}^{2}$ en su $2^{a}$ categoría,. Al ser aprobadas estas últimas se suprimen las Protegidas y Bonificables pues las ayudas se sistematizan dentro de las primeras.

Es decir, la superficie de la vivienda, no responde a programas diferentes de hogares; las viviendas de superficie mínima tienen un programa completo de salacomedor-cocina, tres dormitorios y aseo, y se conciben para familias de 4 a 8 miembros; a medida que aumenta el número de estos, el incremento de $\mathrm{m}^{2}$ es desproporcionadamente pequeño con un dormitorio más, pero la solución realmente consiste en sustituir camas por literas. Desde los años 1940 mejora el cuarto de baño que pasa de una cabina para el retrete y utilización del fregadero como lavabo, a colocar un lavabo en el aseo, y más tarde una ducha, que se convertirá en bañera a lo largo de los años 1960. Tanto las superficies de las viviendas e incluso el desdoblamiento de cuarto de baño completo y aseo, solo se producirá en la Operación de Remodelación y Realojamiento de Barrios en Madrid de los años 1980.

El problema de la vivienda social persiste hasta nuestros días porque hay razones de base que permanecen en la democracia, y no han surgido verdaderas políticas que hayan tratado de encauzarlas. La inmigración del franquismo fue una auténtica oleada, difícil de asimilar en poco tiempo. Entonces eran nacionales procedentes de un medio rural empobrecido como corresponde a un sistema de propiedad de la tierra y su explotación, de tiempos arcaicos. La irrupción de inmigrantes extranjeros a partir de los años 1990, ha sido igualmente rápida pero podemos decir que no tan marginada como la primera. La mayoría de la inmigración de la etapa franquista se situó en infraviviendas en la periferia madrileña, en este caso, considerada como "un cinturón rojo" por la burguesía vencedora de la Guerra. Una y otra lo forman una mano de obra poco cualificada cuyo refugio laboral es la construcción, pero pagada con salarios bajos (en el año 2007 el precio de la construcción en España era 2/3 partes de la Alemana ${ }^{51}$ ), que por una parte hace más rentable el negocio de la construcción y por otro contribuye al poco desarrollo de su industrialización.

Los esfuerzos del Instituto Torroja, que funciona desde el año 1934, no tiene más que un pálido reflejo en algunos materiales y técnicas constructivas que no son mayoritarias. Situación que nos despega de otros países europeos como Alemania, Suiza, Francia o Inglaterra que iniciaron en décadas anteriores su camino hacia la producción en serie de elementos desde su previa normalización en 1937, y en algunos casos redujeron los costes reales hasta un $30 \%$ frente a la construcción

\footnotetext{
50 Según demuestra el trabajo de investigación que realiza el Grupo de "Vivienda Social", titulado "Análisis urbanístico de conjuntos con vivienda pública [VP] en la ciudad de Madrid, 1940-2010" dirigido por L. Moya y coordinado por C. Fernandez Salgado, explotando la base de datos del catastro, la vivienda pública madrileña, en este período solo es más pequeña que la privada en los años 1950 (pendiente de publicación).

51 Véase La Vivienda Social en Europa: Alemania, Francia y Países Bajos, Coord. L. Moya, Ed. Mairea 2008
} 
artesanal $^{52}$. En realidad Walter Gropius venía propugnando lo mismo desde la primera década del S XX con el argumento de inscribir la arquitectura en el sistema de producción industrial. En España hubiera hecho falta una auténtica política en este sentido para homogeneizar el dimensionado, favorecer los componentes reconocidos y premiar de alguna manera a los que utilizaran el sistema industrial. De esta forma se hubiera conseguido, a medio y largo plazo abaratar la construcción mejorando su calidad, cualificar la mano de obra haciéndola más segura con un trabajo en mejores condiciones ambientales y al mismo tiempo fomentar el sector industrial, hoy en franca decadencia. Por otra parte la construcción industrializada por componentes en otros países nos demuestra que la seriación produce más variación y belleza que la construcción con métodos anticuados ${ }^{53}$. En 1956 el recién estrenado Ministerio de la Vivienda convocó un concurso que tenía prácticamente las mismas intenciones que se han puesto aquí de manifiesto y en paralelo con la Interbau de Berlín 1957, pero no prosperó por la fuerza de la tendencia contraria y predominante.

Con todo ello hemos sido testigos de una Dictadura que prometía miles de viviendas pero que no era capaz de construir, y ahora una democracia que promete empleos que no puede generar. Tanto en un régimen como en el otro aumenta progresivamente el déficit de viviendas y empleos en las grandes ciudades. Ambas variables son la base de una buena administración pero ambas son irresolubles cuando están sometidas al mercado libre. Su relación además es directa y ya planteaba en el S XIX en Europa, un conflicto entre industriales e inmobiliarios, a pesar de los esfuerzos hechos por la Administración, y en algunos casos por los propios industriales construyendo sus poblados junto a las fábricas. En un sistema como el español, es incompatible favorecer la tenencia en propiedad de la vivienda, y al mismo tiempo la llamada flexibilidad, o mejor precariedad en el empleo, pues sin una cierta estabilidad laboral los jóvenes no pueden emanciparse y adquirir una vivienda. Además el escaso todavía mercado del alquiler y su carestía, empeora la situación, por tres razones fundamentales: el apoyo fiscal a la vivienda en venta, la inseguridad jurídica y la falta de flexibilidad en la gestión.

En conclusión para mejorar el acceso a la vivienda con condiciones suficientes de habitabilidad para todo el mundo en España, se necesita comenzar inmediatamente una reestructuración del sector con el objetivo de su utilización y no de su comercialización, al tiempo que se mejora la construcción mediante su industrialización. Implica cambios en legislaciones fundamentales como la fiscalidad, la propiedad horizontal, el alquiler, el patrimonio, etc. y también nueva organización administrativa que apoye a los usuarios y no a los promotores. Este proceso no puede estar sometido a las vicisitudes políticas con sus discursos habituales repletos de promesas imposibles, porque como todo cambio de base, necesita tiempo y estabilidad.

\footnotetext{
52 Pepa Casinello La vivienda experimental: concurso de viviendas experimentales de 1956, coord. José M. Fernández Isla, Ed. COAM 1997.

53 Julián Salas et alt. Estrategias para incentivar la industrialización de la Construcción Ed. Ministerio de Fomento 2011
} 